\title{
Interphase Precipitation of VC and Resultant Hardening in V-added Medium Carbon Steels
}

\author{
Goro MIYAMOTO, ${ }^{1,4)}$ Ryota HORI, ${ }^{2)}$ Behrang POORGANJ| ${ }^{3,4)}$ and Tadashi FURUHARA ${ }^{1,4)}$ \\ 1) Institute for Materials Research, Tohoku University, 2-1-1 Katahira, Aoba-ku, Sendai, Miyagi, 980-8577 Japan. \\ 2) Formerly \\ Graduate Student of Tohoku University. Now at TOYOTA MOTOR Corp. \\ 3) Robert R. McCormick School of Eng. \& \\ Applied Science, Northwestern University, 2145 Sheridan Rd., Evanston, IL, 60208-3100 USA. \\ 4) Consortium of the Japan \\ Research and Development Center for Metals for Fundamental Studies on Technologies for Steel Materials with Enhanced \\ Strength and Functions, Japan.
}

(Received on June 6, 2011; accepted on July 14, 2011)

\begin{abstract}
Interphase precipitation of vanadium carbide (VC) accompanying ferrite and pearlite transformations and its effect on hardness have been examined by using medium carbon steels containing $0.1,0.3$ and 0.5 mass \%V. Specimens transformed in a temperature range between 873 and $973 \mathrm{~K}$ consist of pearlite and small amount of proeutectoid ferrite. Ferrite fraction increases with raising transformation temperature or with increasing the $\mathrm{V}$ content. In addition to proeutectoid ferrite and pearlite, bainite is formed below 853 $\mathrm{K}$, whose fraction is increased by the $\mathrm{V}$ addition. Hardening is significant in the $\mathrm{V}$-added alloy between 873 $\mathrm{K}$ and $973 \mathrm{~K}$ and becomes larger by increasing $\mathrm{V}$ content in this temperature range. Meanwhile the alloying effect of $V$ on the hardness remarkably decreases at $823 \mathrm{~K}$ where bainite transformation takes place partly. TEM characterization has revealed that $\mathrm{VC}$ are precipitated in both of proeutectoid and pearlitic ferrite with holding Baker-Nutting (B-N) orientation relationship with ferrite in the manner of fine rows parallel to the austenite / ferrite interphase boundary. Single variant of VC, whose habit plane is closer to ferrite / austenite boundary than the other two B-N variants, tends to be formed. The size of VC decreases and its number density increases by lowering transformation temperature, corresponding to the larger hardness increase.
\end{abstract}

KEY WORDS: precipitation strengthening; ferrite; pearlite; vanadium; transformation.

\section{Introduction}

In order to weight saving of automobiles for reduction of fuel consumption, medium carbon steels for forging parts, such as shaft, connecting rod and so on, are required to be strengthened. One way for achieving higher strength is to use fine precipitates. When carbide forming elements such as $\mathrm{Ti}, \mathrm{Nb}, \mathrm{V}, \mathrm{Cr}$ and Mo are alloyed to carbon steels, it has been frequently reported that alloy carbides are nucleated repeatedly at a growing ferrite / austenite boundary during ferrite transformation, leading to formation of precipitates in rows parallel to ferrite / austenite boundary. ${ }^{1-8)}$ This peculiar precipitation phenomenon is called as interphase precipitation (IP) and has been investigated extensively in low carbon steels. $^{1-8)}$ Recently, interphase precipitation of $\mathrm{Ti}$ carbides in low carbon steels has attracted much attention for developing high strength low carbon sheet steels. ${ }^{9}{ }^{10)}$ It is known that interphase precipitation also takes place in the pearlitic ferrite lamellae in the same manner as in the proeutectoid ferrite in medium and high carbon steels containing carbide forming elements. However, there are few studies on interphase precipitation in medium and high carbon steels ${ }^{11-13)}$ and precipitates formed through interphase precipitation in these steels have not been characterized quantitatively.
In this study, vanadium carbide (VC) is selected for precipitates because a solubility product of $\mathrm{VC}$ in austenite is much larger than that for $\mathrm{TiC}$ or $\mathrm{NbC}$ so that a large amount of $\mathrm{V}$ can be dissolved in medium carbon steels during heating and precipitated through interphase precipitation during cooling. Then, variations in hardness and microstructure including a size and a number density of $\mathrm{VC}$ by the $\mathrm{V}$ addition have been investigated.

\section{Experimental Procedure}

Plain and $\mathrm{V}$-added medium carbon steels containing 0.1 mass $\%, 0.3$ mass $\%$ and 0.5 mass $\% \mathrm{~V}$ were used. These alloys are referred as base, $0.1 \mathrm{~V}$-added, $0.3 \mathrm{~V}$-added and $0.5 \mathrm{~V}$-added alloys, respectively. Nominal compositions and $A_{e}, A_{e 1}$ and dissolution temperatures of $\mathrm{V}(\mathrm{C}, \mathrm{N})$ for these alloys calculated by using ThermoCalc are shown in Table 1. Homogenization treatment of the alloys was performed at $1453 \mathrm{~K}$ for $172.8 \mathrm{ks}$ in silica tube encapsulated with Ar gas to avoid decarburization. Then, these specimens are austenitized for $0.6 \mathrm{ks}$ at $1423 \mathrm{~K}$ for the base alloy or at $1473 \mathrm{~K}$ for the $\mathrm{V}$-added alloys and subsequently transformed isothermally in a salt bath at temperatures ranging from $723 \mathrm{~K}$ to $973 \mathrm{~K}$ for various time periods, followed by quenching into water. Similar nominal grain sizes of prior austenite 
ranging from about 340 to $410 \mu \mathrm{m}$ were obtained by the above treatments in the base and V-added alloys. Vickers hardness of the heat treated specimens was measured by using a load of 9.8 N. Microstructures after transformation were characterized by means of optical, scanning ion and transmission electron microscopies (OM, SIM and TEM, respectively). Specimens for OM were prepared by mechanical polishing followed by electro-polishing by using a solution of $100 \mathrm{~g} \mathrm{CrO}_{3}+20 \mathrm{ml} \mathrm{H}{ }_{2} \mathrm{O}+500 \mathrm{ml} \mathrm{CH} 3 \mathrm{COOH}_{\text {, }}$ then subsequently etched by $3 \%$ nital. Volume fractions of austenite transformed were quantified by point counting method. TEM thin foil specimens were obtained by electropolishing by using the same etchant or by microsampling technique with focused ion beam facilities. These thin foils were observed with TEM (Philips CM300) operated at 300 $\mathrm{kV}$. In order to quantify the number density of VC particles, a local foil thickness of an observed field of view was estimated by a convergent beam electron diffraction method. ${ }^{14)}$

\section{Results and Discussions}

\subsection{Optical Miscrostructure and Hardness}

Figures 1(a), 1(b) and 1(c) show optical microstructures of the base, $0.3 \mathrm{~V}$-added and $0.5 \mathrm{~V}$-added alloys transformed at $963 \mathrm{~K}$ or $973 \mathrm{~K}$, respectively. The base alloy was not transformed at $973 \mathrm{~K}$ fully even after being held for 14.4 ks so that the alloy was transformed at $963 \mathrm{~K}$ instead. All the three alloys consist of pearlite and proeutectoid ferrite structures formed at austenite grain boundary and within the grain. Morphology of proeutectoid ferrite is allotriomorphic at the grain boundary and idiomorphic within the austenite grains. By increasing $\mathrm{V}$ content, fraction of proeutectoid ferrite, especially intragranular ferrite presumably nucleated on inclusions, ${ }^{15-18)}$ increases remarkably. Figures 1(d), 1(e) and 1(f) show effects of transformation temperature on optical microstructure of the $0.3 \mathrm{~V}$-added alloy. By lowering transformation temperature from $973 \mathrm{~K}$ (Fig. 1(b)) to $923 \mathrm{~K}$ (Fig. 1(d)) or $873 \mathrm{~K}$ (Fig. 1(e)), fraction of ferrite decreases and morphology tends to film-like at the grain boundary while pearlite structure becomes more dominant. On the other hand, at $823 \mathrm{~K}$ (Fig. 1(f)), bainite in a form of acicular ferrite are formed at prior austenite grain boundaries as well as inside of austenite grains and fraction of proeutectoid ferrite and pearlite decreases. Bainite was also formed in the base alloy transformed at the same temperature while its amount is much lower than that in the $0.3 \mathrm{~V}$-added alloy.

Figure 2 shows variations in volume fraction of austenite transformed at various temperatures as a function of holding time. At the high temperature (Fig. 2(a)), V addition accelerates austenite decomposition although it takes long holding time for completion of transformation. At 923K, such difference of transformation kinetics between the alloys decreases (Fig. 2(b)). In contrast, V-added alloys exhibit slower transformation kinetics than that in the base alloy at 873 K (Fig. 2(c)).

Figure 3(a) shows variations of hardness of the specimens just after completion of transformation, which correspond to the shortest holding time of fully transformed condition in Fig. 2, as a function of transformation temperature. Hardness of the base alloy increases by lowering

Table 1. Chemical compositions and $\mathrm{A}_{\mathrm{e} 3}, \mathrm{~A}_{\mathrm{e} 1}$ and dissolution temperatures of $\mathrm{V}(\mathrm{C}, \mathrm{N})$ for the alloys calculated by using ThermoCalc.

\begin{tabular}{|c|c|c|c|c|c|c|c|c|c|c|c|c|}
\hline & $\mathrm{C}$ & $\mathrm{Si}$ & $\mathrm{Mn}$ & $\mathrm{V}$ & $\mathrm{P}$ & $\mathrm{S}$ & $\mathrm{Al}$ & $\mathrm{N}$ & $\mathrm{Fe}$ & $\mathrm{A}_{\mathrm{e} 3}[\mathrm{~K}]$ & $\mathrm{A}_{\mathrm{e} 1}[\mathrm{~K}]$ & $\begin{array}{c}\text { Dissolution } \\
\text { temperature of } \\
\mathrm{V}(\mathrm{C}, \mathrm{N})[\mathrm{K}]\end{array}$ \\
\hline $0.1 \mathrm{~V}$-added & 0.44 & 0.25 & 0.85 & 0.1 & 0.015 & 0.016 & 0.030 & 0.0041 & Bal. & 1028 & 984 & 1292 \\
\hline $0.3 \mathrm{~V}$-added & 0.44 & 0.25 & 0.85 & 0.29 & 0.014 & 0.016 & 0.030 & 0.0044 & Bal. & 1035 & 986 & 1383 \\
\hline
\end{tabular}
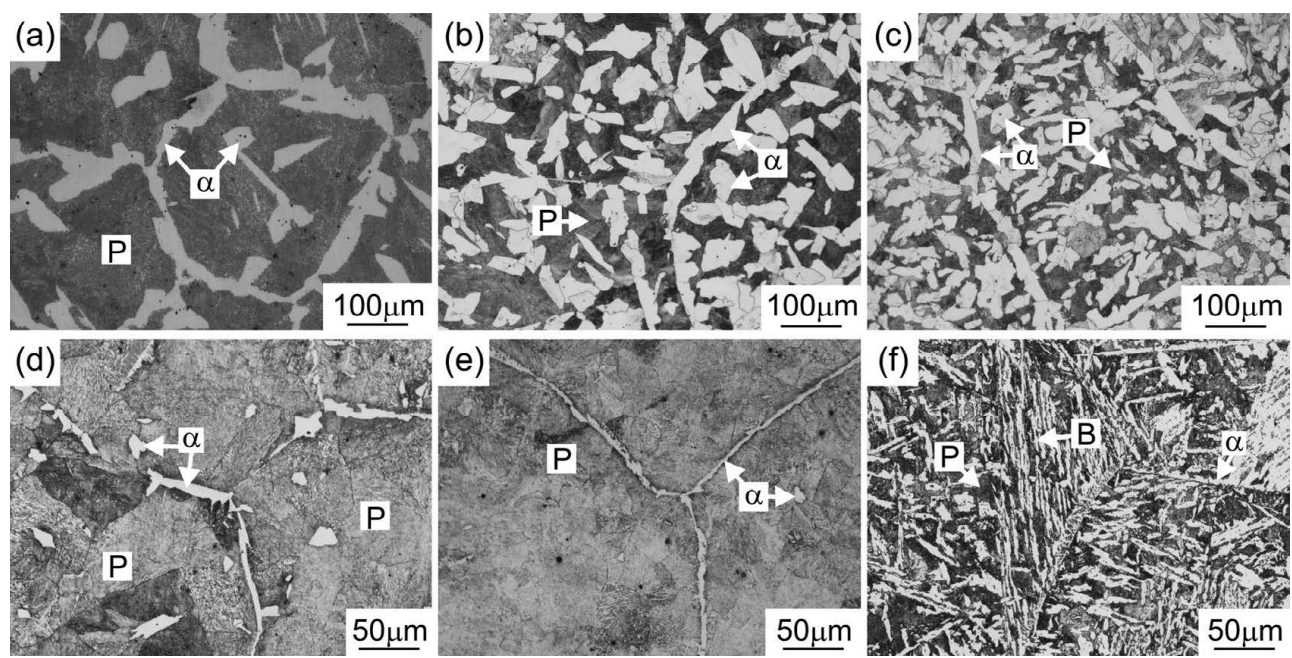

Fig. 1. Optical micrographs, (a) base alloy transformed at $963 \mathrm{~K}$ for $14.4 \mathrm{ks}$, (b) $0.3 \mathrm{~V}$-added alloy transformed at $973 \mathrm{~K}$ for $7.2 \mathrm{ks}$, (c) $0.5 \mathrm{~V}$-added alloy transformed at $973 \mathrm{~K}$ for $7.2 \mathrm{ks}, 0.3 \mathrm{~V}$-added alloys transformed at (d) $923 \mathrm{~K}$ for $120 \mathrm{~s}$, (e) $873 \mathrm{~K}$ for $120 \mathrm{~s}$ and (f) $823 \mathrm{~K}$ for $600 \mathrm{~s}$. 

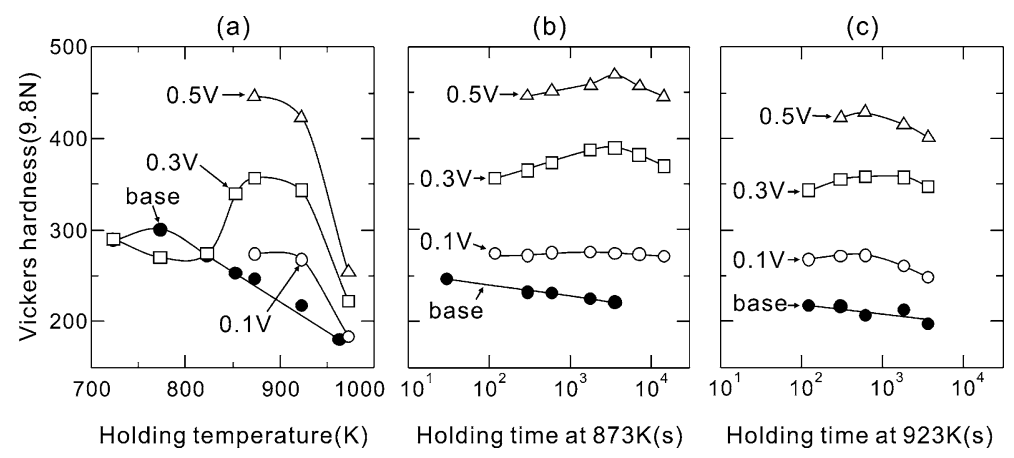

Fig. 3. Variation in hardness, (a) just after transformation at various temperatures, aging after completion of transformation at (b) $873 \mathrm{~K}$ and (c) $923 \mathrm{~K}$.

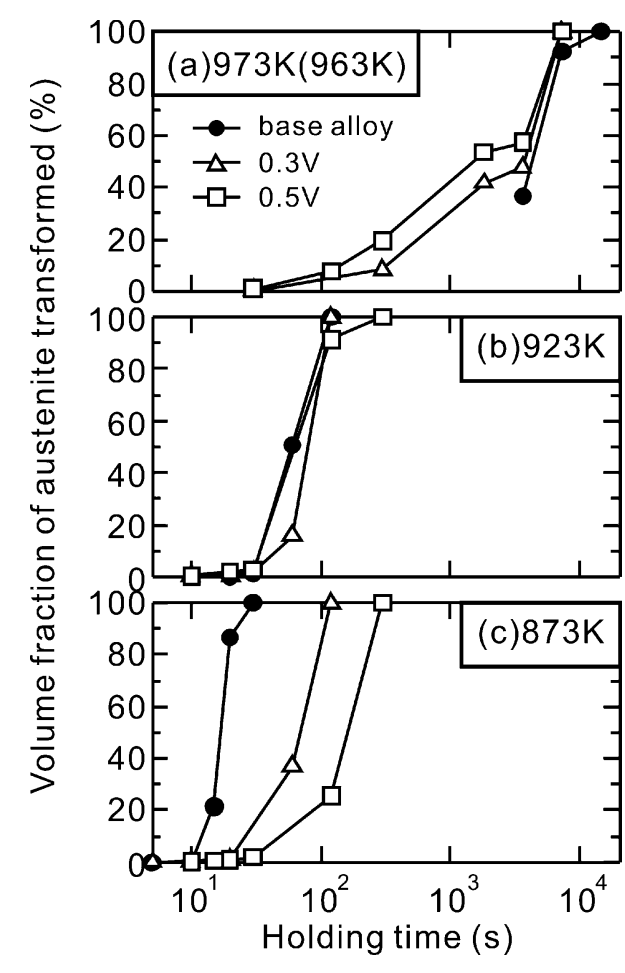

Fig. 2. Variations in volume fraction of austenite transformed at various temperature as a function of holding time. Holding temperatures are (a) $973 \mathrm{~K}$ (963 K for the base alloy), (b) $923 \mathrm{~K}$, (c) $873 \mathrm{~K}$, respectively.

transformation temperature until $773 \mathrm{~K}$. The $\mathrm{V}$ addition results in a significant increase in hardness around $873 \mathrm{~K}$ and hardening by $\mathrm{V}$ alloying increases by increasing V content at temperatures ranging from $873 \mathrm{~K}$ to $973 \mathrm{~K}$. However, hardness of the $0.3 \mathrm{~V}$-added alloy decreases remarkably at temperatures below $853 \mathrm{~K}$ where bainite is formed partially. Aging experiments after completion of transformation were carried out. Figures 3(b) and 3(c) show variations of hardness as a function of holding time at $873 \mathrm{~K}$ and $923 \mathrm{~K}$, respectively. The base alloy is softened monotonously with increasing holding time due to spheroidization of pearlite structure at both temperatures. On the other hand, the Vadded specimens exhibit age - hardening and later, softening by over-aging. Such hardening behavior is more obvious by increasing $\mathrm{V}$ content or at lower aging temperature. Figure 4 shows variations in maximum hardness at various temperatures as a function of $\mathrm{V}$ content. Peak hardness increases

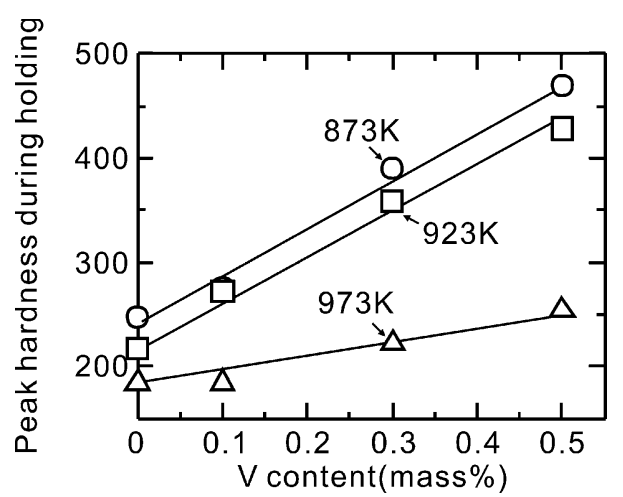

Fig. 4. Effects of the V content on maximum hardness during holding at various temperatures.

linearly against $\mathrm{V}$ content at all the three temperatures while the slope at $973 \mathrm{~K}$ is smaller than these at $873 \mathrm{~K}$ and $923 \mathrm{~K}$.

Hardening by the $\mathrm{V}$ addition is caused by precipitation of VC. Figures 5(a) and 5(b) show dark field TEM images taken from (002) reflection of VC in grain boundary ferrite of the $0.3 \mathrm{~V}$-added alloy transformed at $973 \mathrm{~K}$ and $923 \mathrm{~K}$, respectively. At both temperatures, straight or curved rows of VC particles are observed. As shown in Fig. 5(a), these sheets of precipitates are parallel to the boundary between proeutectoid ferrite and austenite (now transformed to martensite), thus these are formed by interphase precipitation. Intersheet spacing is clearly changed even within the same ferrite grain and it tends to be decreased with approaching the ferrite / austenite boundary (Fig. 5(a)), which is in contrast to nearly the constant spacing of interphase precipitation of $\mathrm{NbC}$ within a ferrite grain of a low carbon steel. ${ }^{8)}$ This fact strongly indicates that migration rate of ferrite / austenite boundary affect intersheet spacing of interphase precipitation as reported elsewhere. ${ }^{19)}$

Figure 6(a) shows SIM image of intragranular ferrite in the $0.3 \mathrm{~V}$-added alloy transformed at $973 \mathrm{~K}$. Thin foil specimens for TEM observation were prepared from the regions $A$ and $B$ indicated in Fig. 6(a). Figures 6(b)-6(d) and Fig. $6(\mathrm{e})$ represent $\mathrm{VC}$ observed at the regions $\mathrm{A}$ and $\mathrm{B}$, respectively. At the region A (Fig. 6(b)), rows of VC parallel to the intragranular ferrite / austenite boundary are seen. Based on selected area diffraction analysis shown in Fig. 6(c), VC is found to hold Baker-Nutting (B-N) orientation relation$\operatorname{ship}\left((001)_{\alpha} / /(001)_{\mathrm{VC}},[110]_{\alpha} / /[100]_{\mathrm{VC}}\right)$ with respect to ferrite matrix, in accordance with literatures. ${ }^{1,2)}$ Although the 

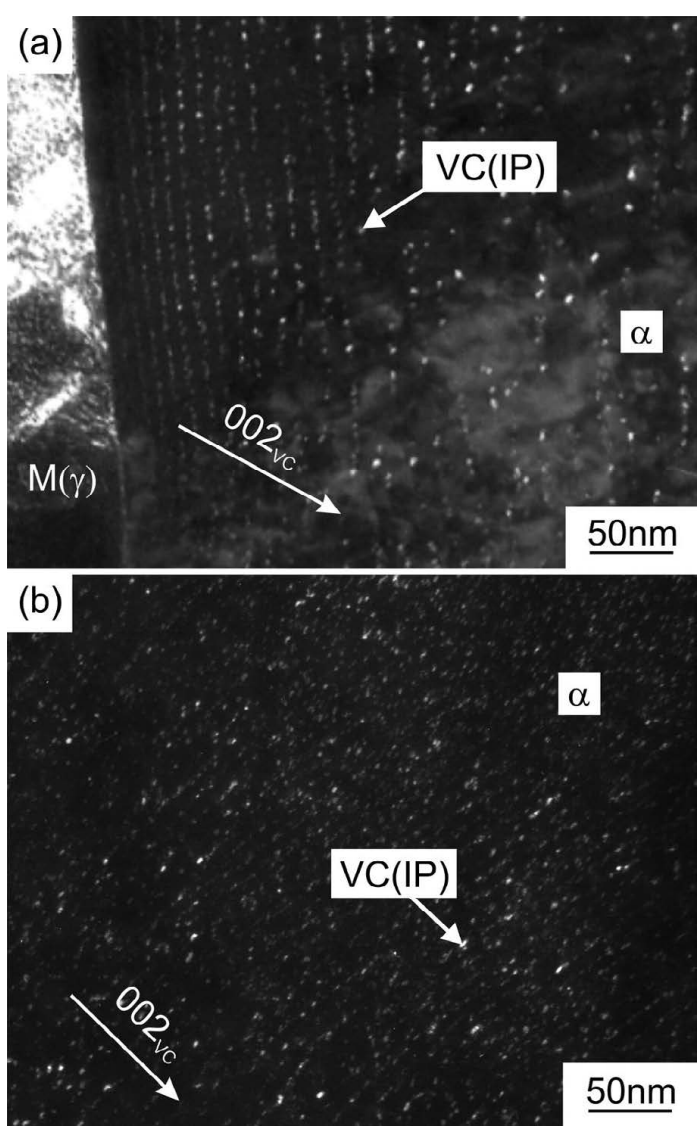

Fig. 5. Dark field TEM images of VC in grain boundary ferrite in the $0.3 \mathrm{~V}$-added alloy transformed at (a) $973 \mathrm{~K}$ for $120 \mathrm{~s}$ and (b) $923 \mathrm{~K}$ for $60 \mathrm{~s}$.

B-N orientation relationship has three equivalent variants, no VC particle is observed (Fig. 6(d)) when the objective aperture was positioned on the possible $(002)_{\mathrm{VC}}$ reflection of another variant for dark field image, which is indicated by an open circle in Fig. 6(c). Thus, it is clear that the single variant of $\mathrm{VC}$ is formed through interphase precipitation. Similarly, interphase precipitation of $\mathrm{VC}$ takes place at the region $\mathrm{B}$ (Fig. 6(e)), but the variant of $\mathrm{VC}$ is different from that in the region A. Habit plane of VC in the B-N orientation relationship is close to $\{001\}_{\alpha}$ which is parallel to (001) Vc. In Figs. 6(b) and 6(e), reflections of (002) $)_{\mathrm{VC}}$ are used for dark field TEM images and its reciprocal vectors are indicated by white arrows. By comparing these arrows and traces of ferrite / austenite boundaries, it is clearly found that the habit plane of the observed variants are closer to the ferrite / austenite boundary than these for the other two variants both at the regions A and B as reported previously. ${ }^{7)}$ This is possibly because grain boundary area diminishing in nucleation of $\mathrm{VC}$ of such variant is larger than the other two variants. In addition to interphase precipitation of $\mathrm{VC}$, fibrous $\mathrm{VC}^{5)}$ are observed as shown in Figs. 6(b) and 6(e), which is nearly perpendicular to the ferrite / austenite boundary. ${ }^{20)}$ It was proposed that a slow migration rate of ferrite / austenite boundary and habit plane of precipitates nearly perpendicular to the ferrite / austenite boundary leads to the formation of fibrous precipitation due to continuous growth of precipitates. ${ }^{20)}$

Figure 7 shows TEM images of VC in pearlitic ferrite in the $0.3 \mathrm{~V}$-added alloy transformed at $923 \mathrm{~K}$. Straight rows
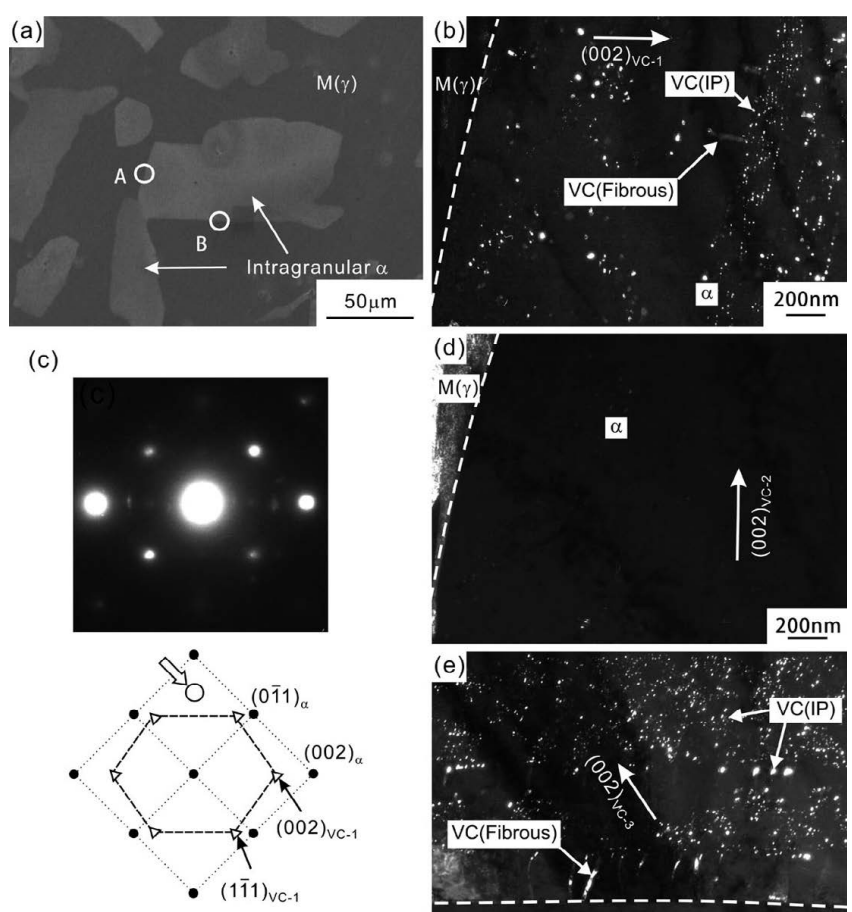

Beam// $[100]_{\alpha} / /[110]_{\mathrm{vc}-1}$

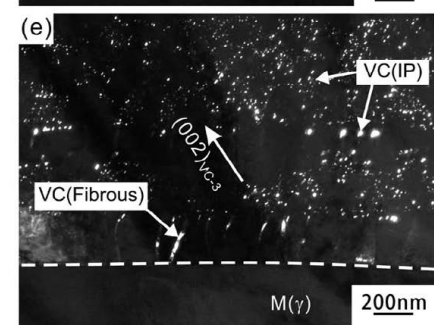

Fig. 6. (a) Scanning ion microscopy image of intragranular $\alpha$ in the $0.3 \mathrm{~V}$-added alloy transformed at $973 \mathrm{~K}$ for $1.8 \mathrm{ks}$, (b) dark field TEM image of $\mathrm{VC}$ at the region $\mathrm{A}$, which is taken from $(002)_{\mathrm{VC}-1}$ reflection, (c) selected area diffraction and its key diagram corresponding to (b), (d) dark field TEM image of $\mathrm{VC}$ at the region A with excitation of $(002)_{\mathrm{VC}-2}$ and (e) dark field TEM image of $\mathrm{VC}$ at the region $\mathrm{B}$, which is taken from $(002)_{\mathrm{VC}-3}$ reflection.
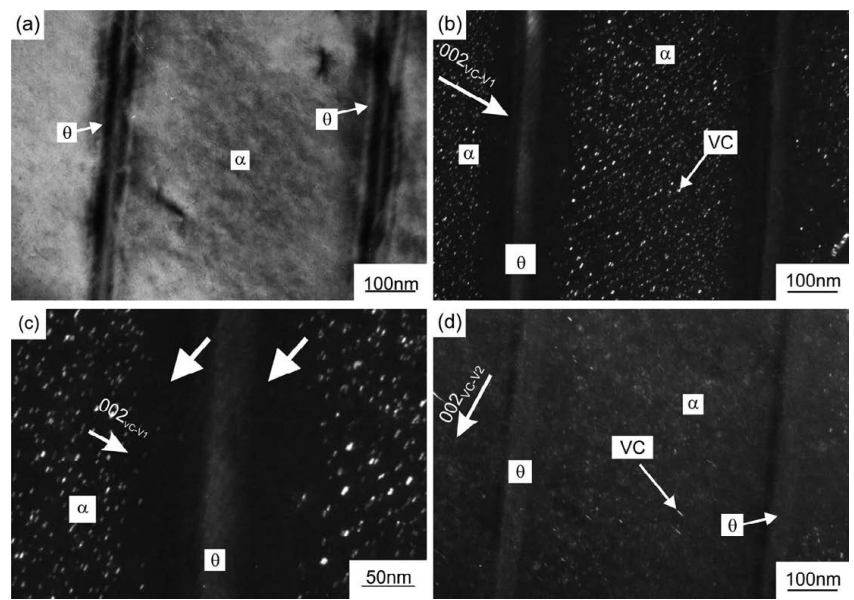

Fig. 7. (a) bright field image of pearlite structure in the $0.3 \mathrm{~V}$ added alloy transformed at $923 \mathrm{~K}$ for $3.6 \mathrm{ks}$, (b) dark field image of $\mathrm{VC}$ taken from $(002)_{\mathrm{VC}-\mathrm{vl}}$, (c) enlarged image of (b) and (d) dark field image of VC taken from $(002)_{\mathrm{VC}-\mathrm{v} 2}$.

of $\mathrm{VC}$ particles are also observed in pearlitic ferrite in the dark field image taken from $(002)_{\mathrm{VC}}$ reflection (Fig. 7 (b)) in agreement with the literatures. ${ }^{11-13,21)}$ Precipitate free zone (PFZ) is observed near the pearlitic cementite lamellae as pointed by solid arrows in Fig. 7(c). Edmonds et al. ${ }^{11,21)}$ similarly reported the formation of PFZ of interphase precipitation of $\mathrm{VC}$ in pearlitic ferrite adjacent to cementite lamellae. They supposed that PFZ are formed because of dissolution of VC around cementite lamellae due to enrich- 
ment of $\mathrm{V}$ into the cementite after transformation, or depletion of $\mathrm{V}$ and carbon near cementite lamellae at the growing austenite / pearlitic ferrite boundary and resultant less nucleation of $\mathrm{VC}$ around cementite lamellae. VC precipitates were found to hold the B-N orientation relationship with respect to pearlitic ferrite. When $(002)_{\mathrm{VC}}$ reflection of the other variant of $\mathrm{B}-\mathrm{N}$ orientation relationship is used for a dark field image, only a few of VC particles are observed as shown in Fig. 7(d), indicating that the single variant of $\mathrm{VC}$ in the B-N orientation relationship is formed dominantly through interphase precipitation in pearlitic ferrite.

Figure 8 represents intersheet spacing of VC at $923 \mathrm{~K}$ and $973 \mathrm{~K}$. The intersheet spacing scatters significantly in the same sample or even within the same ferrite grain as shown in Fig. 5(a) although it tend to be smaller by lowering transformation temperature. Interestingly, clear difference of intersheet spacing at $923 \mathrm{~K}$ between proeutectoid and pearlitic ferrites is not seen. Note that symbols for pearlitic ferrite at $923 \mathrm{~K}$ are plotted at slightly lower temperature than the actual one in order to avoid overlapping with these for proeutectoid ferrite. Such variations in intersheet spacings of $\mathrm{VC}$ in proeutectoid and pearlite ferrite are in good accordance with previous studies. ${ }^{11,22,23)}$ It is supposed that increasing driving force for nucleation of $\mathrm{VC}$ with lowering transformation temperature leads to smaller intersheet spacing. This is also supported by finer intersheet spacing of $\mathrm{VC}$ in higher $\mathrm{V}$ content as shown in Table 2.

Figure 9 displays variation in dispersion of $\mathrm{VC}$ in proeutectoid ferrite ((a), (b)) and pearlitic ferrite ((c), (d)) with transformation temperature. By lowering transformation temperature from $973 \mathrm{~K}$ (Fig. 9(a)) to $923 \mathrm{~K}$ (Fig. 9(b)), sizes of $\mathrm{VC}$ particles decreases while a number density increases in proeutectoid ferrite. Such tendency is similarly observed in pearlitic ferrite as shown in Fig. 9(c) (923 K) and Fig. 9(d) $(873 \mathrm{~K})$. At the same transformation temperature, the size and number density of VC particles are similar in proeutectoid and pearlite ferrites as shown in Figs. 9(b) and 9(c). Note that VC particles formed through interphase precipitation are not spherical but mostly elongated along $(002)_{\mathrm{VC}}$ plane which is habit plane of $\mathrm{VC}$ and parallel to $(001)_{\alpha}$ in the B-N OR.

Such variations in the size and number density of $\mathrm{VC}$ are quantified based on dark field images of $\mathrm{VC}$ and local thin foil thickness estimated by CBED technique. Only the dark field TEM images of VC taken along near [100] $\alpha$ zone axis are used for the quantification since dark field images of two variants can be observed in the same field of view. As shown in Fig. 10, it is assumed that a VC particle is oblate spheroid parallel to the incident beam because of the habit plane of VC holding B-N OR parallel to $(001)_{\alpha}$ plane. Therefore, lengths of major and minor axes of the particle, $l_{1}$ and $l_{2}$ respectively, can be acquired directly from a dark field image in addition to an apparent radius of the particle $\left(r_{a p p}\right)$, which is a radius of a circle having the same area of the particle in the image. When a true radius of the particle $(r)$ is defined as a radius of a sphere having the same volume as that of the oblate spheroid, $r$ is obtained by

$$
\mathrm{r}=\mathrm{r}_{\mathrm{app}} \cdot\left(\mathrm{l}_{1} / \mathrm{l}_{2}\right)^{1 / 6}
$$

Then, mean radius $(\bar{r})$ is estimated by averaging $r$ for all particles in the micrograph. Two variants of VC particles in the

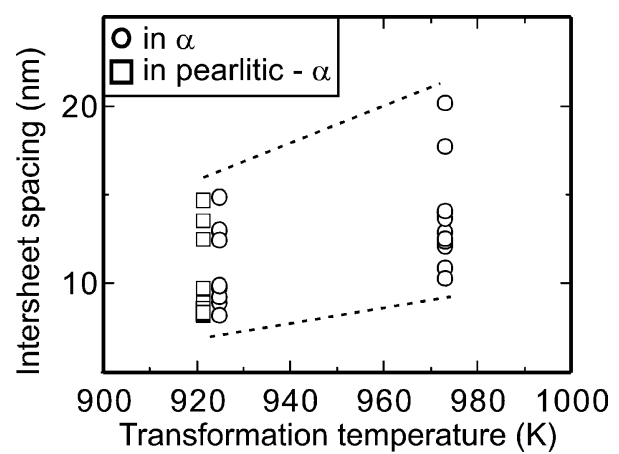

Fig. 8. Variation in intersheet spacing of interphase precipitation of VC with transformation temperature.

Table 2. Comparing intersheet spacing between $0.3 \mathrm{~V}$ and $0.5 \mathrm{~V}$ added alloys transformed at $923 \mathrm{~K}$.

\begin{tabular}{lcc}
\hline & \multicolumn{2}{c}{ Intersheet spacing $(\mathrm{nm})$} \\
\cline { 2 - 3 } & Proeutectoid $\alpha$ & Pearlitic $\alpha$ \\
\hline 0.3 V-added alloy & $11.0 \pm 2.3$ & $10.3 \pm 2.5$ \\
0.5 V-added alloy & $8.3 \pm 2.3$ & $9.4 \pm 1.3$ \\
\hline
\end{tabular}
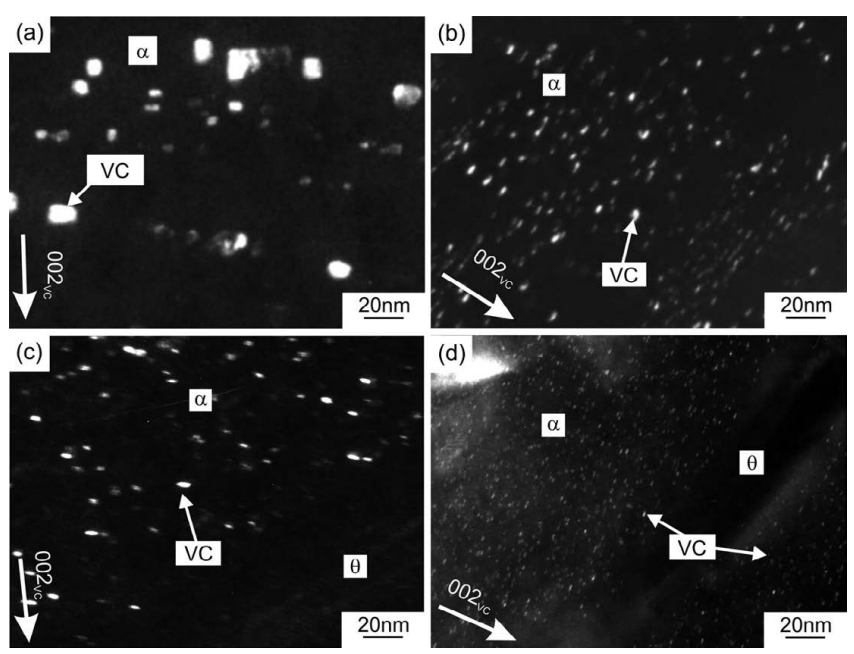

Fig. 9. Dark field TEM images of VC of intephase precipitateion, in proeutectoid ferrite formed at (a) $973 \mathrm{~K}$ for $1.8 \mathrm{ks}$, (b) $923 \mathrm{~K}$ for $120 \mathrm{~s}$, in pearlitic ferrite formed at (c) $923 \mathrm{~K}$ for $120 \mathrm{~s}$ and (d) $873 \mathrm{~K}$ for $3.6 \mathrm{ks}$.

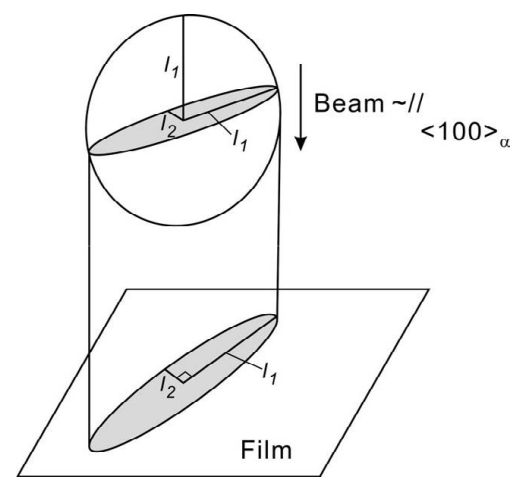

Fig. 10. Schematic illustration of an oblate spheroid VC particle and its projection on a film.

B-N orientation relationship can be observed in the same field of view while remaining one variant cannot be excited for dark field observation. Therefore, total number density 
of VC particles $\left(\rho_{\text {total }}\right)$ is estimated from densities of these two variants as follows;

$$
\rho_{\text {total }}=\rho_{\mathrm{V} 1}+2 \times \rho_{\mathrm{V} 2}
$$

where $\rho_{\mathrm{V} 1}$ and $\rho_{\mathrm{V} 2}$ are number densities of $\mathrm{VC}$ particles for dominant and sparse variants, respectively. Here, number densities of the two sparse variants are assumed to be the same.

Figures 11(a) and 11(b) show variations in the size and number density of $\mathrm{VC}$ particles as a function of a holding time at various temperatures, respectively. At $973 \mathrm{~K}$, the VC size increases and the number density decreases by increasing holding time, indicating that coarsening of VC particles takes place. At $923 \mathrm{~K}$ and $873 \mathrm{~K}$, such variations with holding time or differences between proeutectoid and pearlitic ferrites are not clearly seen. It is found that finer dispersion of VC particles having a higher number density is obtained at a lower transformation temperature, leading to the greater increase in hardness in addition to refinement of interlamellar spacing and increase in volume fraction of pearlite.

The increment in hardness by the $\mathrm{V}$ addition is examined based on the precipitation hardening model. Hardness increase by the $\mathrm{V}$ addition $(\Delta \mathrm{HV})$ is converted into increase in a shear stress $\left(\Delta \tau_{\exp }\right)$ by using empirical formula where hardness is three times larger than yield stress and Tayler factor of non-textured bcc metals (2.08) as follows;

$$
\Delta \tau_{\exp }=\frac{3 \cdot \Delta \mathrm{HV}}{2.08}
$$

$\Delta \mathrm{HV}$ is difference in hardness between the $\mathrm{V}$-added and base alloys transformed at the same condition.

Increase in a yield shear stress by $\mathrm{VC}$ precipitates is calculated by the Ashby-Orowan model; ${ }^{24,25)}$

$$
\Delta \tau_{\text {calc }}=0.84\left(\frac{1.2 \mathrm{~Gb}}{2 \pi \mathrm{L}}\right) \ln \left(\frac{\lambda}{2 \mathrm{~b}}\right)
$$

where $\mathrm{L}$ is a spacing between particles in the slip plane, $\mathrm{G}$ is a shear modulus $(83.1 \mathrm{GPa}), \mathrm{b}$ is Burgers vector $(0.248$ $\mathrm{nm}), \lambda$ is an outer cut off distance. $\mathrm{L}$ is calculated by using a parameter of $x$ which is the diameter of a circle having the same area as the mean area of all circles of intersection; ${ }^{24}$

$$
\mathrm{L}=\frac{1}{\sqrt{2 \overline{\mathrm{r}} \rho}}-\mathrm{x}
$$

$$
\mathrm{x}=2 \overline{\mathrm{r}} \sqrt{\frac{2}{3}}
$$

In the original Ashby-Orowan model, ${ }^{24,25)} \lambda$ is taken to be $x$. Figure 12(a) shows comparison between $\Delta \tau_{\text {calc }}$ by the original model and $\Delta \tau_{\text {exp }}$. It is found that all the $\Delta \tau_{\text {calc }}$ values are apparently smaller than $\Delta \tau_{\text {exp }}$. There are some possibilities causing this discrepancy such as missing small VC particles or clusters in TEM observation and uncertainty in conversion from Vickers hardness to yield strength. In addition, another possibility due to the precipitation model itself can be considered. By taking $\lambda$ as a fitting parameter and equal to $3 \cdot x$, the discrepancy between experiments and calculations can be eliminated as shown in Fig. 12(b). This fitting corresponds to an assumption that an elastic field around dislocation extends to a region three times larger than $x$. It has been frequently reported that $\Delta \tau_{\text {calc }}$ obtained by the original Ashby-Orowan model ( $\lambda$ is taken to be $x$ ) is in good agreement with precipitation strengthening by inter-

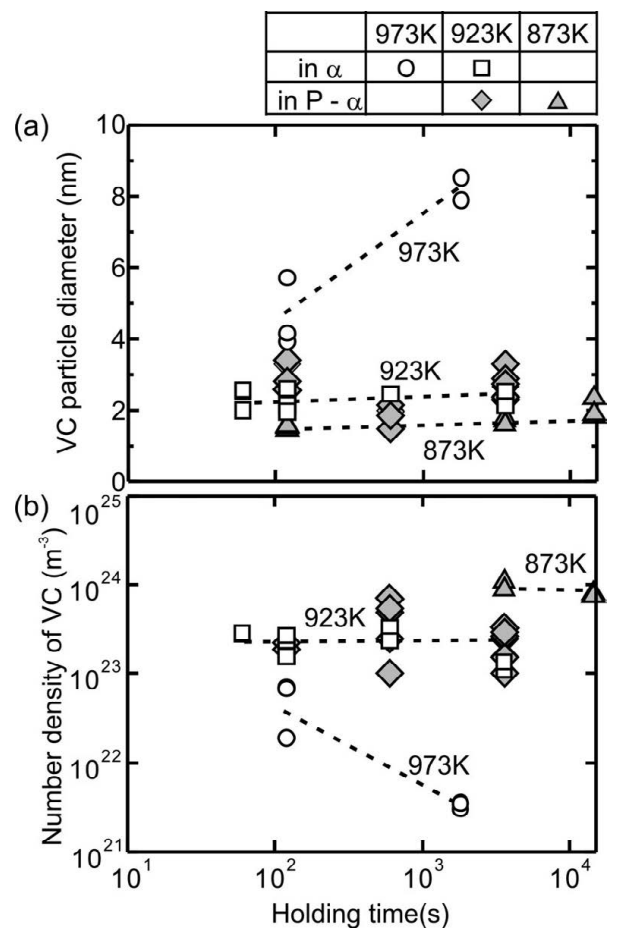

Fig. 11. (a) size and (b) density of VC particles with a holding time and temperature quantified from dark field TEM images. (a)

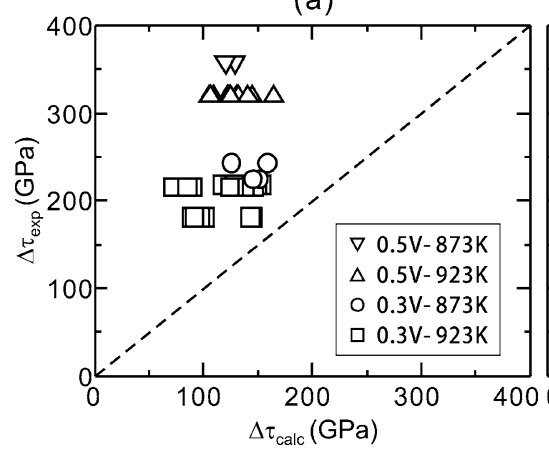

(b)

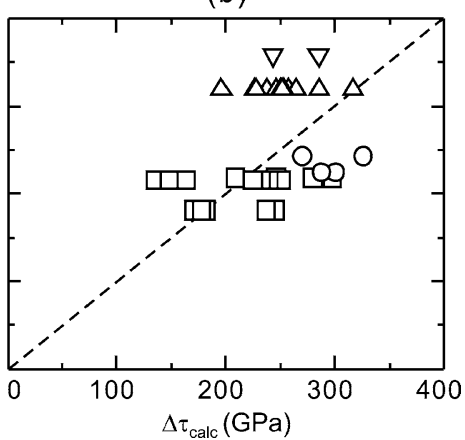

Fig. 12. Comparison of increase in strength by precipitates between calculation based on Ashby-Orowan model and experiments, (a) original Ashby-Orowan model where $\lambda=x$ and (b) modified Ashby-Orowan model assuming $\lambda$ to be $3 x$. 
phase precipitation carbide. In such studies, precipitation strengthening are calculated by assuming that all the carbide forming elements or carbon in the specimens are precipitated. ${ }^{10,26)}$ In contrast, the size and number density quantified in TEM analysis are used in this study, and measured volume fractions are less than that in the equilibrium state predicted by using ThermoCalc software in most cases. This fact implies that the Ashby-Orowan model needs further modification for describing actual strengthening by fine precipitate. Therefore, systematic study on quantification of nano-sized carbide in ferritic or pearlitic single constituent structure is needed in corporate with investigation of tensile behavior of them. The relationship between yield strength and fine carbide formed through interphase precipitation will be reported in elsewhere.

\section{Summary}

Effects of vanadium addition to medium carbon steels on microstructure and hardness of the specimen transformed isothermally were investigated. Obtained results are summarized as follows;

(1) Pearlite and a small amount of proeutectoid ferrite are formed between $873 \mathrm{~K}$ and $973 \mathrm{~K}$. The fraction of ferrite decreases with lowering transformation temperature or with decreasing $\mathrm{V}$ content. Below $873 \mathrm{~K}$, bainite is contained in part, which increases in volume by the $\mathrm{V}$ addition.

(2) The $\mathrm{V}$ addition increases hardness significantly when the specimen is transformed above $873 \mathrm{~K}$. Below 853 $\mathrm{K}$, hardness of the $\mathrm{V}$-added specimen drastically decreases because of bainite formation. Age hardening and subsequent softening by overaging is appeared during the aging at 873 $\mathrm{K}$ and $923 \mathrm{~K}$ after completion of transformation.

(3) Characteristic parallel rows of VC holding of BakerNutting orientation relationship forms through interphase precipitation in proeutectoid and pearlitic ferrites. A specific Baker-Nutting variant, whose habit plane is closer to ferrite / austenite boundary than the other two variants, tends to be formed preferentially. With lowering transformation temperature, dispersion of $\mathrm{VC}$ becomes finer in size and higher in number density.

(4) Precipitation strengthening calculated by the AshbyOrowan model based on the quantified size and number density of VC particles are smaller than the observed hardness increase so that modified Ashby-Orowan equation is proposed for describing precipitation hardening in $\mathrm{V}$-added medium carbon steels.

\section{Acknowledgements}

This study was conducted as a part of the "R\&D on Fundamental Technology for Steel Materials with Enhanced Strength and Functionality" funded by the New Energy and Industrial Technology Development Organization (NEDO).

\section{REFERENCES}

1) A. T. Davenport, F. G. Berry and R. W. K. Honeycombe: Met. Sci. J., 2 (1968), 104.

2) F. G. Berry and R. W. K. Honeycombe: Metall. Tran., 1 (1970), 3279.

3) A. T. Davenport and R. W. K. Honeycombe: Proc. R. Soc. Lond. A, 322 (1971), 191.

4) A. Youle, B. Ralph, S. Freeman and R. W. K. Honeycombe: Metallography, 7 (1974), 333.

5) K. Campbell and R. W. K. Honeycombe: Met. Sci., 8 (1974), 197.

6) T. Sakuma and R. W. K. Honeycombe: Met. Sci., 18 (1984), 449.

7) R. W. K. Honeycombe: Phase transformation in ferrous alloy, The Metall. Soc. of AIME, Pennsylvania, (1984), 259.

8) R. Okamoto, A. Borgenstam and J. Agren: Acta Mater., 58 (2010), 4783.

9) K. Tomita, Y. Funakawa, T. Shiozaki, E. Maeda and T. Yamamoto: Materia Jpn., 42 (2003), 70.

10) Y. Funakawa, T. Shiozaki, K. Tomita, T. Yamamoto and E. Maeda: ISIJ Int., 44 (2004), 1945.

11) S. A. Parsons and D. V. Edmonds: Mater. Sci. Technol., 3 (1987), 894.

12) D. S. Zhou and G. J. Shiflet: Metall. Trans. A, 22A (1991), 1349.

13) N. Ridley, M. T. Lewis, W. B. Morrison: Proc. Int. Conf. Advances in the physical metallurgy and applications of steels, Metals Society, London, (1981), 199.

14) D. B. Williams, C. B. Carter: Transmission electron microscopy, Plenum Press, New York, (1996), 321.

15) F. Ishikawa, T. Takahashi and T. Ochi: Metall. Mater. Trans. A, 25A (1994), 929.

16) I. Nomura and T. Kato: Tetsu-to-Hagané, 82 (1996), 61.

17) T. Furuhara, J. Yamaguchi, N. Sugita, G. Miyamoto and T. Maki: ISIJ Int., 43 (2003), 1630.

18) G. Miyamoto, T. Shinyoshi, J. Yamaguchi, T. Furuhara, T. Maki and R. Uemori: Scr. Mater., 48 (2003), 371.

19) T. Murakami, H. Hatano, G. Miyamoto and T. Furuhara: CAMP-ISIJ, 22 (2009), 1174.

20) D. V. Edmonds: J. Iron Steel Inst., 210 (1972), 363.

21) F. A. Khalid and D. V. Edmonds: Mater. Sci. Tech., 9 (1993), 384

22) A. D. Batte and R. W. K. Honeycombe: J. Iron Steel Inst., 211 (1973), 284

23) N. K. Balliger and R. W. K. Honeycombe: Metall. Trans. A, 11A (1980), 421.

24) T. Gladman: Physical Metallurgy of Microalloyed Steels, Maney Publishing, London, (2002), 52.

25) M. F. Ashby: Proc. 2nd Bolton Landing Conf., Oxide Dispersion Streghthening, Gordon and Breach, New York, (1968), 143.

26) T. Gladman, B. Holmes and I. D. McIvor: Proc. Conf. Effect of second-phase particles on the mechanical properties of steel, Iron and Steel Institute, London, (1971), 68. 